\title{
Late dislodgment of a prosthesis after mitral valve-in-valve implantation
} Rachid Zegdi, MD, PhD, ${ }^{\mathrm{a}, \mathrm{d}}$ Bachir Allam, MD, ${ }^{\mathrm{b}}$ Arschid Azarine, $\mathrm{MD},{ }^{\mathrm{c}}$ and Didier Blanchard, MD,${ }^{\mathrm{b}}$ Paris,
France

From the Service de chirurgie cardiovasculaire, ${ }^{\mathrm{a}}$ Service de chirurgie cardiologie, ${ }^{\mathrm{b}}$ and service de radiologie, ${ }^{\mathrm{c}}$ Hôpital Européen Georges Pompidou; and Université René Descartes, ${ }^{\mathrm{d}}$ Paris, France.

Disclosures: Authors have nothing to disclose with regard to commercial support. Received for publication Oct 2, 2013; revisions received Nov 13, 2013; accepted for publication Nov 20, 2013; available ahead of print March 4, 2014.

Address for reprints: Rachid Zegdi, MD, PhD, Service de Chirurgie Cardiovasculaire, Hôpital Européen Georges Pompidou, 20, rue Leblanc 75908, Paris, France (E-mail: rzegdi@hotmail.com).

J Thorac Cardiovasc Surg 2014;147:e59-61

$0022-5223 / \$ 36.00$

Copyright (c) 2014 by The American Association for Thoracic Surgery http://dx.doi.org/10.1016/j.jtcvs.2013.11.067
A 56-year-old woman was hospitalized for hematuria during December 2012. During examination she complained of dyspnea at exertion. A new systolic murmur was heard at auscultation.

Her past medical history mainly included rheumatic heart disease. She underwent mitral valve repair in 1978. A double mitroaortic valve replacement with Perimount bioprostheses (Edwards Lifesciences, Irvine, Calif) was performed first in 1988 and then in 1997. Recurrence of severe mitral valve regurgitation (MR) occurred during June

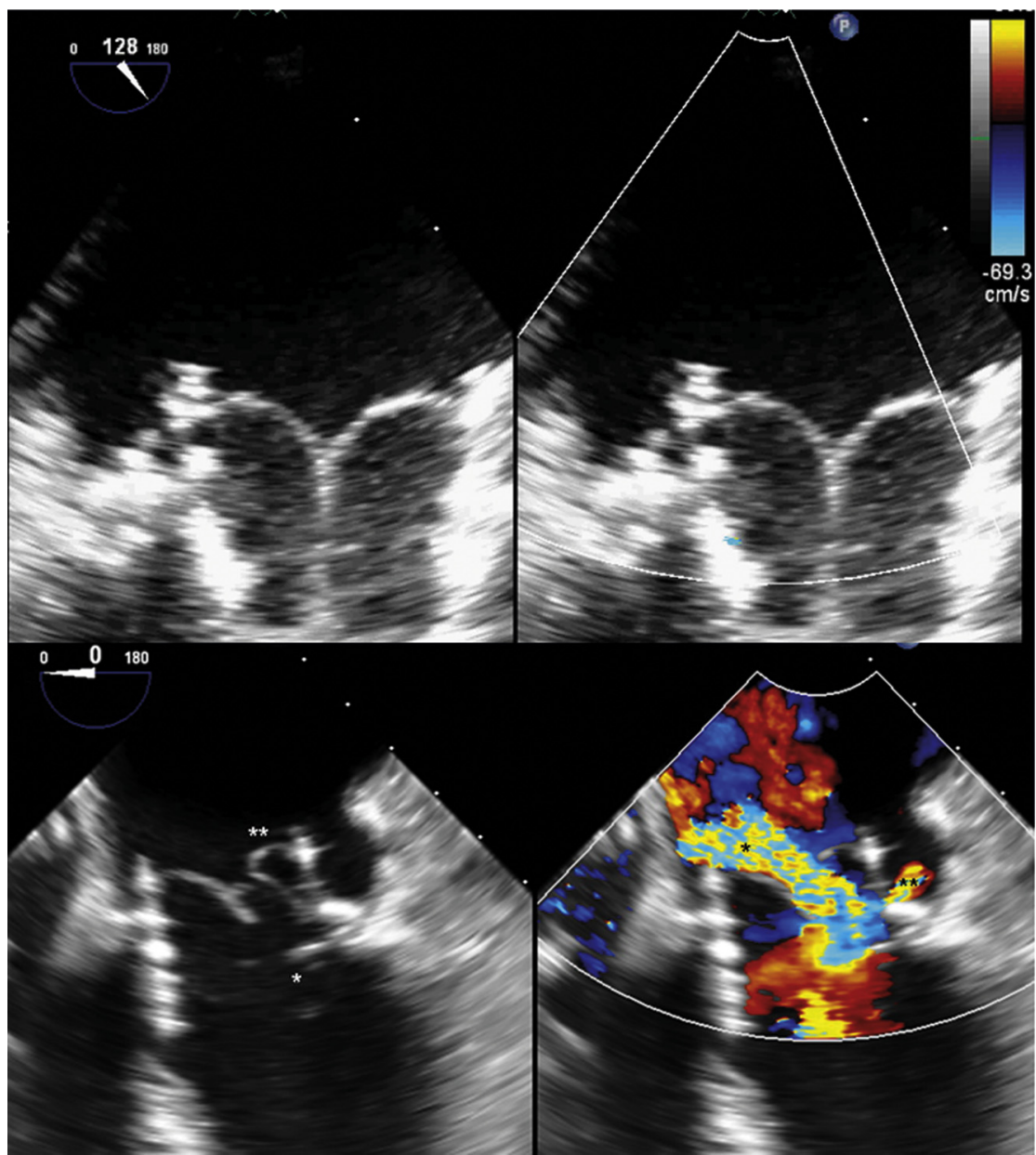

FIGURE 1. Top, Intraoperative transesophageal echocardiographic (TEE) view of the Sapien XT prosthesis (Edwards Lifesciences, Irvine, Calif) immediately after mitral valve-in-valve implantation. The prosthesis function was excellent. Bottom, Intraoperative TEE view of the failed mitral valve-in-valve implant. Bottom left, Backward displacement of the Sapien XT prosthesis was responsible for the uncovering of the leaflets $(*)$ from the failed Perimount prosthesis (Edwards Lifesciences). Note the restrictive leaflet from the Sapien XT prosthesis (**). Bottom right, Color Doppler view showing the intraprosthetic $(*)$ and transprosthetic $(* *)$ jets of mitral regurgitation. 


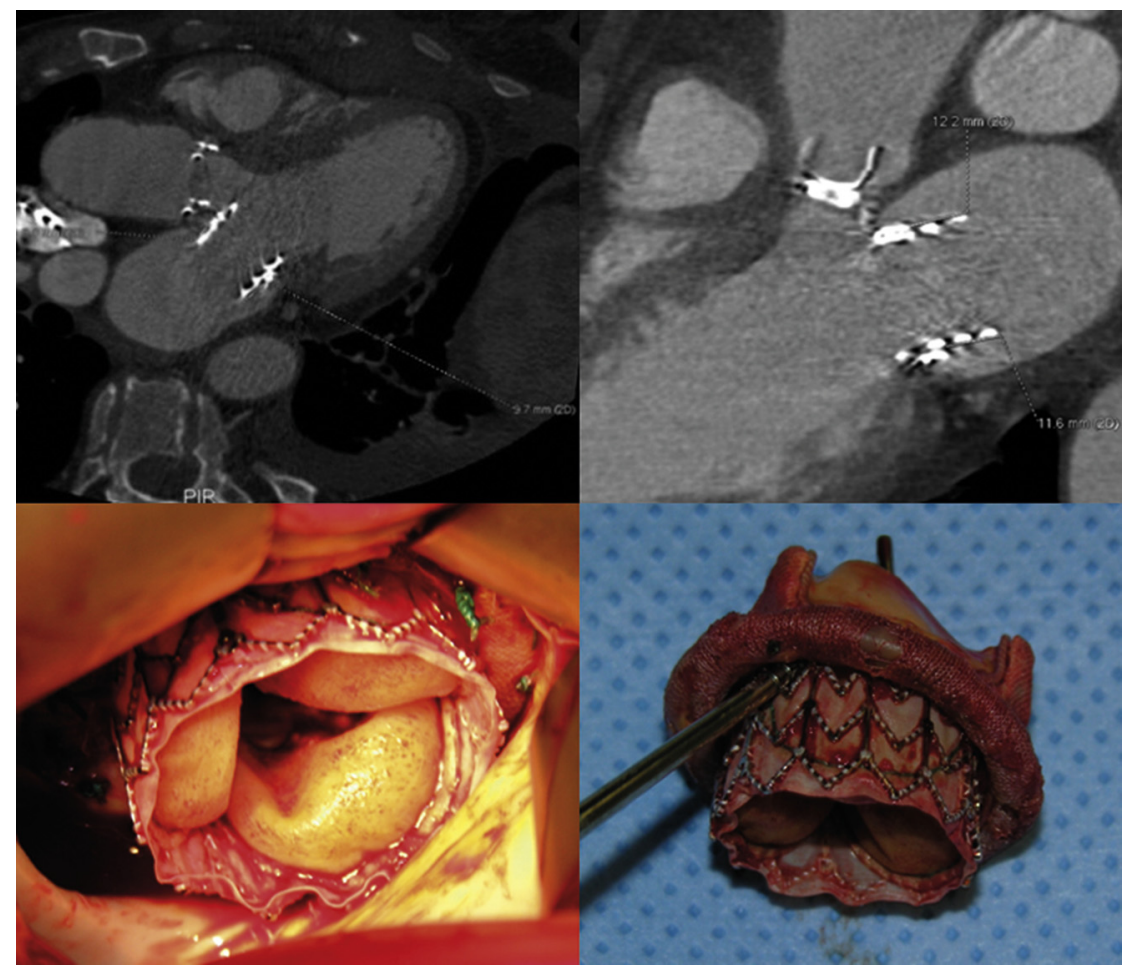

FIGURE 2. Computed tomography scans showing the backward displacement of the Sapien XT prosthesis (Edwards Lifesciences, Irvine, Calif) over time. Top left, Five days after valve-in-valve implantation. Top right, 18 months after valve-in-valve implantation. Bottom, Macroscopic findings during surgery for late failure of mitral valve-in-valve implantation. Bottom left, Surgical view confirming the backward displacement of the Sapien XT prosthesis deployed within the failed mitral Perimount prosthesis (Edwards Lifesciences). Bottom right, Ex vivo view showing the mechanism of the transprosthetic radially oriented jet of mitral regurgitation.

2011. This was related to prolapse of 1 leaflet secondary to structural valve deterioration.

Despite an intermediate risk (logistic Euroscore, 11\%) the patient was considered at high risk for surgery because of severe concomitant pulmonary hypertension (systolic pressure, $87 \mathrm{~mm} \mathrm{Hg}$ ) and the multiple previous sternotomies. The patient therefore underwent transapical mitral valve-in-valve (ViV) implantation during June 2011. A 29-mm Sapien XT prosthesis (Edwards Lifesciences) was uneventfully implanted under fluoroscopy within the $29-\mathrm{mm}$ mitral Perimount prosthesis. The prosthesis overlapped the sewing ring of the failed bioprosthesis. Intraoperative transesophageal echocardiography confirmed excellent mitral prosthesis function (Figure 1). On postoperative computed tomography scan, the height of the atrial part of the Sapien prosthesis varied from 8 to $10 \mathrm{~mm}$ (Figure 2). Until the recent hospitalization, the patient had been asymptomatic with excellent prosthesis function on repeated transthoracic echocardiogram.

Recurrence of severe MR 17 months after the ViV implant was attributed to backward slippage of the previously implanted Sapien XT prosthesis. On computed tomography scan, the height of the atrial part of the Sapien XT was almost $13 \mathrm{~mm}$ (Figure 2). Secondary to this dislodgment, the leaflets of the mitral Perimount prosthesis became uncovered and mobile (Figure 1). One leaflet from the Sapien XT prosthesis had an intermittent restrictive pattern of motion. Two jets of MR were visible. One, totally intraprosthetic, was related to the restrictive motion of 1 leaflet from the Sapien XT prosthesis (Figure 1). The second jet originated from the lumen of the Sapien XT prosthesis and radially crossed the stent of the percutaneous valve. This was due to the fact that following prosthesis dislodgment the distal extremity of the fabric skirt of the Sapien XT prosthesis was upstream of the sewing ring of the mitral Perimount prosthesis (Figure 2).

As a result of the severity of MR, a double mitral and aortic valve replacement was performed with 2 mechanical bileaflet prostheses. The intraoperative findings revealed the backward displacement of the prosthesis and confirmed the mechanism of the lateral jet of MR (Figure 2). The explanted Sapien prosthesis was macroscopically normal. The postoperative course of the patient was uneventful.

Only a few dozen mitral ViV implants have been reported. ${ }^{1,2}$ Despite this, at least 4 cases (including ours) of delayed prosthesis migration have been described. ${ }^{1,3}$ 
Thus, this complication is not infrequent and might therefore be a real concern in the future.

The reasons for occurrence of such a complication are multifactorial. First, the conjunction of a high transvalvular (systolic) gradient applied to large size prosthesis leads to an increased retrograde migration force. Second, too much atrial protrusion of the prosthesis may favor its retrograde displacement. This could have been the case in our patient. Third, underexpansion of the prosthesis might play a major role. This can result from inadequate sizing (which seemed not to be the case with our patient) rather than a technical problem (eg, balloon rupture or insufficient filling volume of the balloon). Fourth, failed bioprosthesis with no or mild leaflet calcification may also be at risk. This was the case in our patient and in another reported on by Bapat and colleagues. ${ }^{3}$ Finally, the stent shape of the deployed prosthesis may have a major role. Some fluoroscopic aspects (eg, rectangular or trapezoidal with the larger base facing the atrial cavity) are prone to secondary migration. The rectangular fluoroscopic aspect was present in the cases reported by Bapat and colleagues ${ }^{3}$ and in our patient.

In the literature, prosthesis migration occurred 6 days to 3 months after the procedure. Clinical presentation was recurrence of dyspnea and of MR at auscultation. The diagnosis was confirmed by transthoracic echocardiogram showing excessive atrial protrusion of the valved stent. Severe mitral dysfunction secondary to retrograde prosthesis migration after mitral ViV has been successfully treated by either surgical mitral valve replacement or redo mitral ViV. ${ }^{1,3}$

Our report is important because it shows that prosthesis dislodgment may occur late ( $>1$ year) after ViV. Close follow-up is mandatory, especially in at-risk patients. Furthermore, due to a probable high risk of delayed migration, criteria for proper prosthesis implantation should be accurately defined in this setting. Our observation with previous reports may also incite valve manufacturers to improve the design of the currently available percutaneous prostheses used for ViV implantation.

\section{References}

1. Cheung A, Webb JG, Barbanti M, Freeman M, Binder RK, Thompson C, et al 5-year experience with transcatheter transapical mitral valve-in-valve implantation for bioprosthetic valve dysfunction. J Am Coll Cardiol. 2013;61: 1759-66.

2. Wilbring M, Alexiou K, Tugtekin SM, Sill B, Hammer P, Schmidt T, et al. Transapical transcatheter valve-in-valve implantation for deteriorated mitral valve bioprosthesis. Ann Thorac Surg. 2013;95:111-8.

3. Bapat VN, Khaliel F, Ihleberg L. Delayed migration of Sapien valve following a transcatheter mitral valve-in-valve implantation. Catheter Cardiovasc Interv. 2014;83:E150-4.

\title{
Percutaneous closure of paravalvular leak in children after left ventricular outflow enlargement by the Konno procedure with aortic valve mechanical prosthesis
}

\author{
Lilia Oreto, MD, ${ }^{\mathrm{a}}$ Fiore Salvatore Iorio, MD, ${ }^{\mathrm{a}}$ Giacomo Pongiglione, MD, FACC, ${ }^{\mathrm{b}}$ and \\ Paolo Guccione, MD, ${ }^{\mathrm{a}}$ Taormina and Rome, Italy
}

A clinically significant paravalvular leak (PVL) is a complication of valve replacement with estimated incidence up to $9 \%$ in adults. ${ }^{1}$ However, the incidence of PVL in children is not reported and its occurrence after

\footnotetext{
From the Mediterranean Pediatric Cardiology Center, ${ }^{\mathrm{a}}$ Bambino Gesù Children's Hospital, Taormina, Italy; and Department of Pediatric Cardiology and Cardiac Surgery, ${ }^{\mathrm{b}}$ Bambino Gesù Children's Hospital, Rome, Italy.

Disclosures: Authors have nothing to disclose with regard to commercial support.

Received for publication Jan 1, 2014; revisions received Jan 27, 2014; accepted for publication Jan 31, 2014; available ahead of print March 6, 2014

Address for reprints: Paolo Guccione, MD, Mediterranean Pediatric Cardiology Center, Bambino Gesù Children's Hospital at San Vincenzo Hospital, Taormina, Italy (E-mail: paolo.guccione@opbg.net).

J Thorac Cardiovasc Surg 2014;147:e61-3

0022-5223/ $\$ 36.00$

Copyright $(2014$ by The American Association for Thoracic Surgery

http://dx.doi.org/10.1016/j.jtcvs.2014.01.047
}

surgical enlargement of the left ventricular outflow tract (LVOT) and the aortic annulus is rarely described. Although a surgical approach has been considered the preferred treatment, it is burdened by high incidence of recurrent leakages and significant morbidity and mortality. ${ }^{1,2}$ During the past decade a percutaneous approach to PVL has been increasingly employed in an effort to overcome surgeryrelated limitations, to the point that successful results are reported in up to $90 \%$ of treated patients. ${ }^{3,4}$ However, transcatheter treatment of PVL in children has been reported after mitral valve replacement but never after aortic valve replacement. ${ }^{5}$ We report the experience of transcatheter closure of aortic PVL in 2 children after they underwent the Konno procedure and prosthetic aortic valve implantation. 